\title{
Does Work-Family Conflict Predict Organisational Commitment Among Rural Working Women in Ebonyi State, Nigeria?
}

\author{
Emmanuel Agwu Arisi-Nwugballa, Ph.D. \\ Department of Business Management \\ Faculty of Management Sciences \\ Ebonyi State University, Abakaliki-Nigeria \\ nwugballa@gmail.com
}

\begin{abstract}
Public sector organisations in Ebonyi State are grappling with counterproductive behaviours suggestive of employees' low commitment to their organisations; a situation that has invoked several government interventions aimed at arresting and reversing the trend. As a contribution to this effort, this study was aimed at ascertaining the extent work-family conflict predicts organisational commitment among rural working women in the State. A field-survey approach was adopted to collect quantitative data from 345 rural working women in three Local Government Areas of Ebonyi State, using an 18 -item, five-point Likert-scaled questionnaire, which yielded 89 per cent response rate. The results of multiple regression analysis showed that time-based and strain-based family-to-work conflict were significant negative predictors of organisational commitment among rural working women, while behaviour-based family-to-work conflict was an insignificant negative predictor of organisational commitment among the population. These findings show that, though issues relating to family-to-work conflict are not popular in public and organisational policies in this part of the world, these issues are, nonetheless, important predictors of organisational commitment, and should be explored in the bid to improve workers' commitment and performance in the workplace.
\end{abstract}

Ke ywords : Work-family conflict, family-to-work conflict, rural working women, organisational commitment, Igbo culture, Ebonyi State, Nigeria.

\section{INTRODUCTION}

Nigerian public sector organisations suffer from employees' perennial inclination to engage in counterproductive attitudes and behaviours e.g. absenteeism, tardiness, indolence at work, leaving the office before the close of work, merchandising at work, demanding and accepting bribes as precondition of rendering services or as illegal rewards for services rendered, etc., resulting in poor individual and organisational performance. There is, generally, a deep-rooted notion that public sector organisations and properties belong to the government and, ironically, belong to nobody. Government is conceived as an abstract entity undeserving of people's emotional attachment. This disposition, probably, emanated from indigenous peoples' sentiments against colonialism, the precursor of modern government and its institutions in Nigeria. Analogously, the Igbo-speaking people of Nigeria refer to public sector employment as oru bekee(white man's job), suggesting lack of indigenous ownership of, or identity with, colonial government and its institutions. The inclination towards emotional detachment from government and its institutions may account for the prevalence of the counterproductive attitudes and behaviours, due to an underlying lack of commitment to the organisation. However, this supposed colonial relic appears to have been assimilated and continues to plague public sector organisations, which has necessitated several government interventions to reorient its employees towards greater commitment to the workplace.

This situation is very prominent in Ebonyi State; one of the Igbo-speaking States in the South-East geo-political zone of Nigeria. Ebonyi State is one of the youngest, poorest and least developed States in the country. The huge developmental needs of the State require effective and efficient public service delivery; hence the obvious need to have employees that are committed to the values and goals of government institutions. Ebonyi State government recognised this point by identifying 'an effective public service, dedicated to excellence and efficiency in service delivery' as a critical factor that was needed for the successful implementation of government programmes in the State [1, p.37]. 


\section{Emmanuel Agwu Arisi-Nwugballa}

Consequently, successive governments have introduced measures and programmes aimed at combating the prevalence of counterproductive attitudes and behaviours amongst its employees, e.g. Attitudinal Change Campaign. This Campaign, introduced in 2008, was intended to help inculcate attitudes and behaviours that are germane to effective and efficient public service. While this paper does not intend to assess the success or failure of the programme, the benefit of hindsight suggests that it (and similar government interventions) need to identify and focus on key variables that significantly predict work-related variables of interest; instead of symptomatic treatment of the counterproductive attitudes and behaviours. This paper seeks to fill this gap by examining the effect of work-family conflict on organisational commitment, with a view to determining whether it is one of the key variables, in Ebonyi State context, that could significantly reduce employees' counterproductive attitudes and behaviours.

\subsection{Literature Review}

Organisational commitment has been variously conceptualised, see [2],[3],[4] and [5]. However, this paper considers organisational commitment as "the relative strength of an individual's identification with and involvement in a particular organisation" [4, p.27]. This involvement includes identifying with its values and goals, willingness to exert effort on its behalf, and a willingness to remain a member of the organisation [6]. An employee's attitudinal commitment to an organisation apparently derives from his/her relationship with the organisation; a relationship that depends on the extent the goals and values of the organisation are compatible with those of the individual [7]. Lack of (affective) organisational commitment has been associated with employee low performance [8], increased tardiness, absenteeism [9], and high labour turnover [10], etc.

Studies have identified several factors that affect organisational commitment, which can be grouped into three namely; personal characteristics, organisational characteristics, and work experience [11]. Personal characteristics include age, gender, educational qualification, tenure, marital status, sense of professionalism, sense of competence, need for achievement, etc., of the employees. For instance, [12] meta-analytic study found positive correlation between affective commitment and age, gender, and tenure, respectively. However, some studies found insignificant negative correlation between age and affective commitment, and insignificant gender differences in organisational commitment, e.g. [13]. Organisational characteristics (e.g. policies, culture, and structure, etc.) that are capable of influencing employees' perception of organisational support may be useful in influencing organisational commitment [14]. Under work experience, studies have found significant negative relationship between role conflict or role ambiguity and organisational commitment, e.g. [15], [16].

Every individual plays several roles in the course of every passing day; as parent, sibling, spouse, employee, employer, church member, community member, etc. A role can be defined as 'culturally defined behavioural expectations that an individual is expected to fulfil' [17, p.446]. Each of the roles has its own demands and expectations, and requires the psychological, physical, and temporal resources of the individual to enact. These roles could be broadly classified into work and non-work (e.g. family) roles. In enacting each role, individuals interact with a role set, which refers to a group of people within a role e.g. spouse, children, parents, relatives (family role set), or managers, supervisors, co-workers, customers, etc. (work role set). It is necessary to point out that the Igbo culture places high premium on family and work roles as key responsibilities of adulthood. Consequently, family and work roles constitute two critical roles for most adults in the Igbo society.

Engagement in multiple roles exposes individuals to situations in which "the sent expectations or demands from one role interfere with the individual's ability to meet the sent expectations or demands from another role", resulting in incompatibilities between roles known as inter-role conflict [18, p.75]. When this conflict is between the demands of work and family roles, it is known as work-family conflict. Work-family conflict is rooted in role theory [19], and predicated on the theory of scarcity of time, human energy, and other personal resources. The scarcity of these resources inhibits an individual's capacity to satisfy the demands and expectations of all the roles they are actively involved in, which leads to role strain and conflict [20]. When an individual expends his/her time, energy or psychological resources on the satisfaction of the demands and expectations of any role; it reduces the amount of these same resources available to the individual to satisfy the demands and expectations of competing roles. 
Work-family conflict is made up of two related but distinct directions namely; work-to-family conflict (WTF) and family-to-work (FTW) conflict [21]. Researchers have also identified three forms of both directions of work-family conflict namely; time-based, strain-based, and behaviour-based workfamily conflict [21]. WTF conflict exists when obligations from work role interfere with family role. Conversely, FTW conflict exists when responsibilities from family role interfere with work role. This study focuses on FTW conflict because it is expected to predominantly affect organisational outcomes than WTF conflict (cross-domain approach) [22].

Time-based conflict exists when multiple roles concurrently contend for an individual's time such that time spent in one role impedes participation in another role. Time is a central factor in all human activities and, like other resources, is limited in supply. Individuals need time to perform their work and family roles, and when responsibilities in both domains demand the attention of an individual at the same time frame, or the fulfilment of a responsibility in one domain encroaches on the (time) schedule of another responsibility in a different domain, it becomes very difficult or impracticable for the employee to effectively perform both responsibilities in both domains, at the same time. This describes time-based conflict and invokes issues of choice and opportunity cost (trade-off). Sources of time-based work-family conflict include inflexible work schedules, schedule conflict, long working hours (work domain) and marital status, family size, age of children, and spouse's working status (family domain) [23], [24], [21], and [25].

Work-family conflict is regarded as strain-based when stressors from one role inhibit individual's ability to enact another role, even though the roles are enacted at different time periods [21]. An individual who experience strain (anxiety, dissatisfaction, fatigue, tension, etc.) at work may transfer same, or its effect on him or her, to the family domain, or vice versa. Strain experienced in one domain has the tendency to interfere with a person's performance in other domains. For example, fatigue from work could make an employee unable to effectively perform some of his obligations to his family. Antecedents such as low spousal support, low supervisor support, work overload, job insecurity [21], [26]; schedules, long working hours, fatigue and irritability [27]; and stress [28], etc., impact on strain-based work-family conflict.

Behaviour-based work-family conflict relates to incompatibilities in expected behaviours across different roles [21]. When specific behaviour required or developed at work is at variance with expected behaviour at home and the individual is unable to switch to the family compatible behaviour, it makes it difficult for him or her to fulfil the demands of family role, and vice versa. Such a conflict is behaviour-based. For example, the aggressiveness and emotional stability required in the work environment may be inappropriate in the family domain, thereby impeding the performance of family role [21].

Incidences of work-family conflict, especially FTW conflict, are expected to be on the increase among rural working women in Ebonyi State because increase in rural poverty rate (73.2\%) [29] compels many of them to take on additional family responsibilities such as providing money for family upkeep and children's education, which were, hitherto, part of men's breadwinning obligations. Therefore, besides their regular salaried work, the women engage in farming and other income generating activities in the bid to cope with increasing family demands on them. These activities are in addition to their traditional role of family caretaking. Rural communities, being repositories of cultural practices, still insist on men not engaging in domestic chores because engagement in those chores are generally regarded as women's traditional family obligation. This practice drastically limits spousal support for working women; apparently exposing them to FTW conflict.

Incidentally, government policy on free and compulsory education has widened access to basic education in Ebonyi State, and that has led to drastic reduction in the supply of house-help services because majority of them could now go to school. In addition, the continuing trend of rural-urban migration means that many of the available house-helps prefer to live in urban areas. Consequently, many rural families find it increasingly difficult to hire house-helps because they live in rural communities. The situation is exacerbated by the increasing individualism of the Igbo society and aperceptible decline in the intensity of the extended family system. Consequently, many out-of-school children and teens are becoming increasingly less inclined to live with their relatives than they were a few decades ago. There are, therefore, fewer helping hands for families; resulting in the intensification of women's direct engagement in their family roles, which could expose them to FTW conflict; especially those with young children. 
Several studies have found that FTW conflict is a significant negative predictor of organisational commitment, e.g. [8], [30], and [31]. However, much of the existing knowledge in this area derives from studies conducted in North America, Europe, and Asia, etc., requiring that studies be conducted in Ebonyi State cultural context to determine the applicability, or otherwise, of existing knowledge to Ebonyi State. Secondly, the researcher is not aware of any other study that sought to determine whether work-family conflict predicts the organisational commitment of a rural working women population as used in this study, which means that the evidence of studies conducted in non-rural areas may not be generalizable to rural working women in Ebonyi State. However, these can only be determined on the evidence of an empirical study such as this. These are the gaps that this present study seeks to fill.

From the literature reviewed, this paper proposed and tested the following hypotheses:

$\mathrm{H}_{0}$ 1: Time-based FTW conflict does not significantly predict the organisational commitment of rural working women in Ebonyi State,

$\mathrm{H}_{0}$ 2: Strain-based FTW conflict does not significantly predict the organisational commitment of rural working women in Ebonyi State,

$\mathrm{H}_{0}$ 3: Behaviour-based FTW conflict does not significantly predict the organisational commitment of rural working women in Ebonyi State.

\section{MeThOdology}

The study adopted a field survey approach to collect quantitative data on the dependent variable (organisational commitment) and independent variables (time-based FTW conflict, strain-based FTW conflict, and behaviour-based FTW conflict) from rural working women, through the use of questionnaire. 345 copies of the questionnaire were distributed to rural working women in 87 publicly-owned institutions in three Local Government Areas of Ebonyi State, Nigeria. 307 usable copies of the questionnaire were retrieved, giving a return rate of 89 per cent. All the respondents were fulltime employees of the Local Government Councils, were married, and had at least one child under the age of eighteen (18).

Multiple regression was used to investigate the predicting effect of the independent variables (timebased, strain-based, and behaviour-based FTW conflict) on the dependent variable (organisational commitment), as well as their relative contributions. Analyses were determined at significance level of 0.05 .

\subsection{Measurements}

FTW conflict was measured using a 9-item instrument that measured FTW conflict across its three forms (i.e. time-based, strain-based, and behaviour-based FTW conflict), on a 5-point Likert scale developed by Carlson, Kacmer, and Williams [32]. The internal consistency of this section of the instrument yielded Cronbach $\alpha$ value of $0.83,0.81$, and 0.83 for time-based, strain-based, and behaviour-based FTW conflict, respectively. Example of the items that measured time-based FTW conflict is: the time I spend with my family often causes me not to spend time in activities at work that could be helpful to my career. Example of the items that measured strain-based FTW conflict is: because I am often stressed from family responsibilities, I have a hard time concentrating on my work; while example of the items that measured behaviour-based FTW conflict is: behaviour that is effective and necessary for me at home would be counterproductive at work.

Organisational commitment was measured using a 9-item instrument that measured organisational commitment as a single construct, on a 5-point Likert scale developed by Mowday, Porter, and Steers [33]. Measuring organisational commitment as a single construct was in consonance with this paper's deference to Mowday, Steers, and Porter's definition of organisational commitment [4]. The internal consistency of this section of the instrument yielded Cronbach $\alpha$ value of 0.89. An example of the items on this section was: I talk of this organisation to my friends as a great organisation to work for.

\section{Presentation of Results/Findings}

Table I below shows the results of multiple regression analysis conducted to test the research hypotheses. The regression analysis had adjusted $\mathrm{R}^{2}$ of 0.712 , which statistically means that the predictors account for 71 per cent of the total variability in the organisational commitment of the population, which is reasonably high. The $F$-statistics $(F=253.195)$ showed that the regression model has a good fit, significant at 0.01 . The table also shows the relative contributions of the predictors to 
Does Work-Family Conflict Predict Organisational Commitment Among Rural Working Women in Ebonyi State, Nigeria?

the organisational commitment of rural working women in Ebonyi State, showing $\beta, t$, and p values as follows:

TableI. Regression analysis and relative contributions of the predictors to organisational commitment

\begin{tabular}{|l|l|l|l|}
\hline Variable & Coefficient & t-Value & $\mathbf{p}<\mathbf{t}>$ \\
\hline Constant & 47.561 & 60.396 & 0.000 \\
\hline Time-based FTW Conflict & -1.344 & -20.910 & 0.000 \\
\hline Strain-based FTW Conflict & -0.237 & -3.483 & 0.001 \\
\hline Behaviour-based FTW Conflict & -0.072 & -1.217 & 0.225 \\
\hline F-Statistic & 253.195 & \\
\hline $\mathrm{p}<\mathrm{t}>$ & 0.000 & \\
\hline Adjusted R-Square & 0.712 & \\
\hline
\end{tabular}

Time-based FTW conflict was a significant negative predictor of organisational commitment for rural working women in Ebonyi State $(\beta=-1.34, t=-20.9, p<0.01)$. This implies that a decrease in the respondents' experience of time-based FTW conflict would significantly improve their organisational commitment.

Strain-based FTW conflict was also a significant negative predictor of organisational commitment of the population $(\beta=-0.24, t=-3.5, p<0.01)$. This implies that a decrease in the respondents' experience of strain-based FTW conflict would significantly improve their organisational commitment.

Behaviour-based FTW conflict was a statistically insignificant negative predictor of the population's organisational commitment $(\beta=-0.07, t=-1.2, p>0.05)$. This implies that a decrease in the respondents' experience of behaviour-based FTW conflict would not significantly improve their organisational commitment.

The stability of above results was tested by regressing FTW conflict (time-, strain-, and behaviourbased) and each of the control variables against organisational commitment, as shown in Appendix I below. To avoid multi-colinearity bias, the control variables were successively introduced in the baseline model and the earlier results (as presented above) remained generally stable. The $\beta$-values, $t$ statistic, probability of $t, F$-statistic, probability of $F$, and adjusted $r^{2}$ all remained within the same range except for some minor differences in decimals. Time-based FTW conflict and strain-based FTW conflict remained significant and negative, while behaviour-based FTW conflict remained insignificant and negative across different functional specifications.

The results, with respect to time- and strain-based FTW conflict, are consistent with the findings of prior studies, e.g. [30] and [31]. Both studies found that both time-based work-family conflict and strain-based work-family conflict were significant negative predictors of organisational commitment in the populations they studied. However, both studies also found that behaviour-based conflict was a significant negative predictor of organisational commitment, which contradicts the finding of this present study namely; that behaviour-based FTW conflict was an insignificant negative predictor of organisational commitment among the population.

\section{CONCLUSiON}

This study found that time- and strain-based FTW conflict are significant negative predictors of organisational commitment among rural working women in Ebonyi State, Nigeria. The study also found that behaviour-based FTW conflict is an insignificant negative predictor of organisational commitment of the population.

A major implication of the findings of this study is that time- and strain-based forms of FTW conflict are important variables in the management of employees towards commitment to the organisation. High level of organisational commitment has been found to motivate employees towards higher levels of job performance, productivity, job satisfaction, organisational citizenship behaviour, etc. It is, therefore, in the best interest of any organisation to evolve policies and practices that would reduce time- and strain-based FTW conflict experience among its employees, in order to improve their commitment to the organisation. In doing this, cross-domain approach suggests that organisations should look in the direction of reducing the level of, and/or pressures from, employees' family role engagement through appropriate policies, such as provision of financial assistance (to enable employees hire house-helps), on-site childcare facilities, flexible work arrangements, etc. 


\section{Emmanuel Agwu Arisi-Nwugballa}

Another implication of the findings of this study is that organisations should pay attention to the family-domain welfare of their employees, not only at work. Organisations' interest in their employees' family experiences should be informed by the realisation that their employees' family roles could positively or negatively interfere with their work role and, by so doing, contribute to causing positive or negative organisational outcomes, as the case may be. In fact, organisations should be interested in taking measures that will help their employees to achieve greater balance between their work and family roles because of the reciprocity of work-family conflict, see [34]. Achieving a good balance between work and family roles would help towards improving employees' psychological and physical wellbeing and, in turn, enable them to make more productive contributions to their organisations.

Reduction of employees' experience of FTW conflict also requires increase in working women's spousal and family support with family responsibilities. Igbo men should learn to support their working spouses by assisting them with their domestic obligations, especially now that free and compulsory education, rural-urban migration, growing de-emphasis on communal way of life, and the devaluation/depreciation of the local currency (naira), etc., have combined to reduce the availability, and increase the cost of hiring house-help services.

A further implication is that the Western-developed instruments used in this study were found to be both valid and reliable. Results of the principal component analysis of the data showed very good (unforced) loadings for all the measures, which showed the validity of the instruments in this study. FTW conflict loaded as three factors, which corresponded with its three forms namely; time-based, strain-based, and behaviour-based conflicts. Organisational commitment loaded as a single factor, which agreed with our single construct approach. Furthermore, the internal consistency of the instruments which yielded Cronbach $\alpha$ value of $0.83,0.81$, and 0.83 for time-, strain-based, and behaviour-based FTW conflict, respectively; and 0.89 for organisational commitment were considered good indicators of the reliability of the instruments. The findings of this study were also consistent with the findings of some extant studies, which suggest that the instruments and findings may not be culture-specific.

Nonetheless, this study was limited by the inherent weaknesses in the use of questionnaire to collect data, and by the use of only quantitative data for a human behavioural study, which would have been enriched by the additional use of qualitative data as observed by Remenyi, Williams, Money, and Swartz [35]. In addition, this study used cross-sectional data, which means that we cannot establish trend. Finally, the number of rural working women surveyed by this study tends to limit the generalisability of its findings, even though its generalisability is enhanced by the cultural correspondence of the entire Ebonyi State, and Igbo culture in general. It may, therefore, be useful to encourage that future studies consider (i) adding qualitative data for purposes of enriching the study; (ii) using longitudinal data to establish trend; and (iii) increasing the number of respondents in order to improve on its generalisability.

\section{REFERENCES}

[1] Ebonyi State Planning Commission, Ebonyi State economic empowerment and development strategy, Abakaliki: Government Press (2006).

[2] Allen, N.J. and Meyer, J.P., The measurement and antecedents of affective, continuance, and normative commitment to the organization, Journal of Occupational Psychology, 63, 1-18 (1990).

[3] Becker, H.S., Notes on the Concept of Commitment, American Journal of Sociology, 66, 32-40 (1960).

[4] Mowday, R.T., Steers, R.M., and Porter, L.W., The measure of organisational commitment. Journal of Vocational Behaviour, 14, 224-247 (1979).

[5] Weiner, Y., Commitment in organization: a normative view, Academy of Management Review, 7, 418-428 (1982).

[6] Porter, L., Steer, R., Mowday, R., and Boulian, P., Organisational commitment, job satisfaction, and turnover among psychiatric technicians, Journal of Applied Psychology, 59(5), 603-609 (1974).

[7] Storey, J., Is HRM catching on? International Journal of Manpower, 16(4), 3-12 (1995). 
[8] Li, C., Lu, J., and Zhang, Y., Cross-domain effects of work-family conflict on organizational commitment and performance, Social Behavior and Personality, 4(10), 1641-1654 (2013).

[9] Kirchmeyer, C, and Cohen, A., Different strategies for managing the work/non-work interface: a test for unique pathways to work outcomes, Work and Stress, 13, 59-73 (1999).

[10] Shaffer, M.A., Harrison, D.A., Gilley, K.M., and Luk, D.M., Struggling for balance amid turbulence on international assignments: work-family conflict, support and commitment, Journal of Management, 27, 99-121 (2001).

[11] Meyer, J.P., and Herscovitch, I., Commitment in the workplace: towards a general model. Human Resources Management Review, 11, 299-326 (2001).

[12] Mathieu, J., and Zajac, D., A review of meta-analysis of the antecedents, correlates and consequences of organizational commitment, Psychological Bulletin, 108(2), 171-194(1990).

[13] Hawkins, W.D., Predictors of affective organisational commitment among high school principals, unpublished doctoral thesis, Virginia Polytechnic Institute and State University (1998).

[14] Meyer, J.P., and Allen, J.N., Commitment in the work place: theory, research and application. Thousand Oaks, CA: Sage, 1997.

[15] Brandt, J., Krawczyk, M.R., and Kalinowski, M.J., Personal and work-related predictors of organizational commitment and life satisfaction of Slovak women in higher education, College Teaching Methods and Styles Journal, 4(2), 7-14 (2008).

[16] Siegel, P.A., Post, C., Brockner, J., Fishman, A.Y., and Garden, C., The moderating influence of procedural fairness on the relationship between work-life conflict and organizational commitment, Journal of Applied Psychology, Jan., 90(1), 13-24 (2005).

[17] Morris, M.L., and Madsen, S.R., Advancing work-life integration in individuals, organisations, and communities, Advances in Developing Human Resources, 9, 439-454 (2007).

[18] Rothbard, N.P., and Dumas, T.L., Research perspective: managing the work home interface, in F. Jones, R.J. Burke, and M. Westman (Eds.), Work-life balance: a psychological perspective (pp. 71-89), New York: Psychological Press (2006).

[19] Frone, M.R., Work-family balance, in J. Campbell Quick and L.E. Tetrick (Eds.), Handbook of Occupational Health Psychology (pp. 143-162), Washington, D.C.: American Psychological Association (2003).

[20] Ruderman, M.N., Ohlott, P.J., Pancer, K., and King, S.N., Benefits of multiple roles for managerial women, Academy of Management Journal, 45, 369-386 (2002).

[21] Greenhaus, J.H., and Beutell, N.J., Sources of conflict between work and family roles. Academy of Management Review, 10, 76-88 (1985).

[22] Amstad, F.T., Meier, L.L., Fasel, U., Efering, A., and Semmer, N.K., A meta-analysis of workfamily conflict and various outcomes with a special emphasis on cross-domain versus matching domain relations, Journal of Occupational Health Psychology, 16(2), 151-169 (2011).

[23] Cinamon, R.G., Anticipated work-family conflict: effects of gender, self-efficacy, and family background, The Career Development Quarterly, 54, 202-215 (2006).

[24] Clark, S.C., Work cultures and work/family balance, Journal of Vocational Behaviour, 58, 348365 (2001).

[25] Greenhaus, J.H., and Kopelman, R.E., Conflict between work and non-work roles: implications for the career planning process, Human Resource Planning, 4, 1-10 (1981).

[26] Small, S.A., and Riley, D., Towards a multi-dimensional assessment of work spillover into family life, Journal of Marriage and the Family, 52, 51-61 (1990).

[27] Jones, A.P., and Butler, M.C., A role transition approach to the stresses of organizationallyinduced family role disruption, Journal of Marriage and the Family, 42, 367-376 (1980).

[28] Voydanoff, P., The effects of work demands and resources on work-to-family conflict and felicitation, Journal of Marriage and Family, 66, 398-412 (2004). 
[29] British Council (2012). Gender in Nigeria report: improving the lives of girls and women in Nigeria, www.britishcouncil.org.ng/files/2012/12/Gender Report-full.pdf, assessed 23/10/2015).

[30] Mohammadi, M., Porkiani, M., and Beheshtifar, M., The study of the relation between workfamily conflict with organizational commitment among the staff of Tejarat Bank branches of Kerman, Applied Mathematics in Engineering, Management and Technology, 2(2), 88-99 (2014).

[31] Zulfigar, A., Kundi, G.M., Qureshi, Q.A., and Khan, N., Evaluating the relationship between work-family conflict and organisational commitment (a survey of nursing staff in public sector hospitals of District Bhakkar, Pakistan, Public Policy and Administration Research, 3(4), 58-63 (2014).

[32] Carlson, D.S., Kacmer, K.M., and Williams, I.J., Construction and initial validation of a multidimensional measure of work-family conflict, Journal of Vocational Behaviour, 56, 249276 (2000).

[33] Mowday, R.T., Porter, I.M., and Steers, R.M., Employee organisational linkage. New York: Academic Press, 1982.

[34] Trensbrunsel, A.E., Brett, J.M., Maoz, E., Stroh, L.K., and Reilly, A.H., Dynamic and static work-family relationships, Organisational Behaviour and Human Decision Process, 63, 233-246 (1995).

[35] Remenyi, D., Williams, B., Money, A. and Swartz, E., Doing research in business and management: an introduction to process and method, London: Sage, 1998.

\section{Appendix I:}

Regression Estimation of the Relationship between Time-based, Strain-based, Behaviour-based FTW Conflict and Organisational Commitment (and Control Variables)

\begin{tabular}{|c|c|c|c|c|c|c|c|c|c|}
\hline & 1 & 2 & 3 & 4 & 5 & 6 & 7 & 8 & 9 \\
\hline $\begin{array}{l}\text { Time-based } \\
\text { FTW Conflict }\end{array}$ & $\begin{array}{l}-0.448 * * \\
(-20.938)\end{array}$ & $\begin{array}{l}-0.448 * * \\
(-20.875)\end{array}$ & \begin{tabular}{|l|}
$-0.449 * *$ \\
$(-20.921)$
\end{tabular} & $\begin{array}{l}-0.448 * * \\
(-20.843)\end{array}$ & $\begin{array}{l}-0.488^{* * *} \\
(-20.870)\end{array}$ & $\begin{array}{l}-0.448 * * \\
(-20.847)\end{array}$ & \begin{tabular}{|l}
$0.447 * *$ \\
$(-20.840)$
\end{tabular} & \begin{tabular}{|l}
$-0.447 * *$ \\
$(-20.855)$
\end{tabular} & $\begin{array}{l}-0.448 * * \\
(-20.884)\end{array}$ \\
\hline $\begin{array}{l}\text { Strain-based } \\
\text { FTW Conflict }\end{array}$ & $\begin{array}{l}0.078^{*} \\
(-3.465)\end{array}$ & $\begin{array}{l}-0.079 * \\
(-3.492)\end{array}$ & $\begin{array}{l}-0.080^{*} \\
(-3.525)\end{array}$ & $\begin{array}{l}-0.079^{*} \\
(-3.450)\end{array}$ & $\begin{array}{l}-0.079^{*} \\
(-3.479)\end{array}$ & $\begin{array}{l}-0.079 * \\
(-3.482)\end{array}$ & $\begin{array}{l}-0.079 * \\
(-3.494)\end{array}$ & \begin{tabular}{|l|}
$-0.080^{*}$ \\
$(-3.510)$
\end{tabular} & $\begin{array}{l}-0.078^{*} \\
(-3.427)\end{array}$ \\
\hline $\begin{array}{l}\text { Behaviour- } \\
\text { based FTW } \\
\text { Conflict }\end{array}$ & $\begin{array}{l}-0.022 \\
(-1.121)\end{array}$ & $\begin{array}{l}-0.024 \\
(-1.235)\end{array}$ & $\begin{array}{l}-0.023 \\
(-1.153)\end{array}$ & $\begin{array}{l}-0.023 \\
(-1.171)\end{array}$ & $\begin{array}{l}-0.024 \\
(-1.187)\end{array}$ & $\begin{array}{l}-0.024 \\
(-1.218)\end{array}$ & $\begin{array}{l}-0.025 \\
(-1.247)\end{array}$ & $\begin{array}{l}-0.025 \\
(-1.244)\end{array}$ & $\begin{array}{l}-0.024 \\
(-1.201)\end{array}$ \\
\hline Age & \begin{tabular}{|l|}
-0.053 \\
$(-1.528)$ \\
\end{tabular} & & & & & & & & \\
\hline $\begin{array}{l}\text { Highest } \\
\text { Qualificat-ion }\end{array}$ & & \begin{tabular}{|l|}
-0.009 \\
$(-.386)$ \\
\end{tabular} & & & & & & & \\
\hline $\begin{array}{l}\text { Husband's } \\
\text { Employ ment } \\
\text { Status } \\
\end{array}$ & & & $\begin{array}{l}0.036 \\
(-0.888) \\
\end{array}$ & & & & & & \\
\hline \begin{tabular}{|l|} 
No. of \\
Children
\end{tabular} & & & & \begin{tabular}{|l|}
-0.010 \\
$(-.245)$ \\
\end{tabular} & & & & & \\
\hline $\begin{array}{l}\text { Age of } \\
\text { Youngest } \\
\text { Child } \\
\end{array}$ & & & & & $\begin{array}{l}-0.003 \\
(-.108) \\
\end{array}$ & & & & \\
\hline Job Cadre & & & & & & $\begin{array}{l}-0.018 \\
(-.365)\end{array}$ & & & \\
\hline $\begin{array}{l}\text { No of Hours } \\
\text { Worked per } \\
\text { week } \\
\end{array}$ & & & & & & & \begin{tabular}{|l}
-0.041 \\
$(-.869)$
\end{tabular} & & \\
\hline $\begin{array}{l}\text { Family } \\
\text { Income }\end{array}$ & & & & & & & & \begin{tabular}{|l}
-0.026 \\
$(-.677)$
\end{tabular} & \\
\hline $\begin{array}{l}\text { Length of } \\
\text { Service } \\
\end{array}$ & & & & & & & & & $\begin{array}{l}-0.020 \\
(-.402) \\
\end{array}$ \\
\hline Constant & \begin{tabular}{|l}
$5.361 * *$ \\
$(53.237)$
\end{tabular} & $\begin{array}{l}5.317 * * \\
(44.131)\end{array}$ & \begin{tabular}{|l}
$5.226^{* * *}$ \\
$(47.612)$
\end{tabular} & $\begin{array}{l}5.294 * * \\
(55.100)\end{array}$ & \begin{tabular}{|l}
$5.288^{* *}$ \\
$(56.874)$
\end{tabular} & $\begin{array}{l}5.317 * * \\
(42.372)\end{array}$ & $\begin{array}{l}5.335^{* *} \\
(50.927)\end{array}$ & \begin{tabular}{|l}
$5.328 * *$ \\
$(48.896)$
\end{tabular} & $\begin{array}{l}5.320 * * \\
(42.604)\end{array}$ \\
\hline F-Statistic & $\begin{array}{l}191.32 * * \\
(0.000)\end{array}$ & $\begin{array}{l}189.4^{* *} \\
(0.000)\end{array}$ & \begin{tabular}{|l}
$189.96^{* * *}$ \\
$(0.000)$
\end{tabular} & \begin{tabular}{|l}
$189.32 * *$ \\
$(0.000)$
\end{tabular} & \begin{tabular}{|l}
$189.28 * *$ \\
$(0.000)$
\end{tabular} & $\begin{array}{l}189.39 * * \\
(0.000)\end{array}$ & $\begin{array}{l}189.93 * * \\
(0.000)\end{array}$ & \begin{tabular}{|l}
$189.67 * *$ \\
$(0.000)$
\end{tabular} & $\begin{array}{l}189.41^{* *} \\
(0.000)\end{array}$ \\
\hline $\begin{array}{l}\text { AdjustedR- } \\
\text { Squared }\end{array}$ & 0.713 & 0.711 & 0.712 & 0.711 & 0.711 & 0.711 & 0.712 & 0.712 & 0.711 \\
\hline
\end{tabular}

$* *<0.01, *<0.05$ 
Does Work-Family Conflict Predict Organisational Commitment Among Rural Working Women in Ebonyi State, Nigeria?

\section{AUTHOR'S BIOGRAPHY}

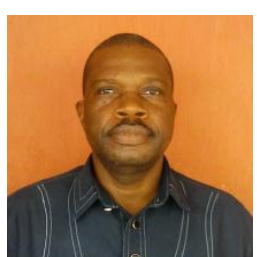

Emmanuel Agwu Arisi-Nwugballa, holds a B.Sc. (Hons.) degree in Economics, MBA, and Ph.D. in Management, specialising in Organisational Behaviour. He is a lecturer in Business Management at Ebonyi State University, Abakaliki, Nigeria. His research interests span from economics to organisational behaviour with specific interests in development, entrepreneurship, organisational theory, workfamily interface, and organisational commitment, an area in which he obtained his Ph.D. Emmanuel is a member of the Nigerian Institute of Management. 